\title{
Pulmonary Function and Its Influence Factors of Residents in Yeosu Industrial Complex
}

\author{
Eun-Ju Hong, Gi-Sub Ahn"), Eun Kyung Chung ${ }^{2)}$, Xinbiao GUO ${ }^{3)}$, Bu-Soon Son \\ Department of Environmental Health Science, Soonchunhyang University, Chungnam 336-745, Korea \\ ${ }^{1)}$ Division of Health \& Environment, Baekseok cultural University, Chungnam 330-705, Korea \\ ${ }^{2)}$ Division of Biological Science, Sookmyung Women's University, Seoul 140-742, Korea \\ ${ }^{3)}$ Department of Occupational \& Environmental Health Sciences, Peking University, Beijing 100-871, China \\ (Manuscript received 5 April, 2011; revised 6 May, 2011; accepted 16 June, 2011)
}

\begin{abstract}
Objectives: This study is aimed at identifying the influential factors on the pulmonary function of ordinary residents in the surrounding areas of Yeosu Industrial Complex. Methods: The PFT (Pulmonary Function Test) was conducted on the target residents numbering 989 people (male 361, female 628). The exposed group ( 813 people) resided within the radius of $5 \mathrm{~km}$ from Yeosu Industrial Complex and the control group (176 people) resided in the radius of more than $15 \mathrm{~km}$ from May 2007 to November 2007. The survey also took into account other factors including personal characteristics, life habits, respiratory diseases and allergic symptoms, medical histories, and the living environments of the residents in order to further identify influential factors on pulmonary function. Result: When comparing the PFT values of the exposure groups to the control group of the same city, values of the exposure groups were meaningfully lower with an $\% \mathrm{FEV}_{1}$ of $107.05 \%$ and $\% \mathrm{FVC}$ of $100.28 \%$. Conversely, the control group reported an $\% \mathrm{FEV}_{1}$ and $\% \mathrm{FVC}$ of $107.26 \%$ and $102.85 \%$ respectively, indicating that ambient air pollutants reduce lung function. The odds ratio of asthma diagnosis history increased when a subjects residence was close to a heavily trafficked road, traffic amount was huge, a bed was used, and the family had less than four members. However the results were not statistically meaningful. The odds ratios of abnormal pulmonary function were statistically higher among those with asthma( $\mathrm{OR}=4.29, \mathrm{CI}=1.75-10.56)$, wheezing $(\mathrm{OR}=2.59, \mathrm{CI}=1.24-5.41)$, and nasal congestion $(\mathrm{OR}=2.87, \mathrm{CI}=1.36-6.08)(\mathrm{p}<0.01)$. The factors affecting $\mathrm{FEV}_{1}$ were symptoms including asthma, passive smoking and allergic eye disease $\left(\mathrm{R}^{2}=0.049, \mathrm{p}<0.001\right)$. For the $\mathrm{FVC}$ symptoms including asthma $\left(\mathrm{R}^{2}=0.014, \mathrm{p}<0.001\right)$ were measured. The analysis showed that FVC decreased with increases in $\mathrm{O}_{3}$ and $\mathrm{CO}(\mathrm{p}<0.01)$. Furthermore, $\mathrm{FEV}_{1}$ decreased with increases in $\mathrm{O}_{3}(\mathrm{p}<0.01)$. Conclusions: These results will provide preliminary data for establishing responsive measures to protect the health of residents in industrial complexes from air pollution, and to develop lasting environmental health policies.
\end{abstract}

Key Words : PFT, FEV 1, FVC, Odds ratio, $\mathrm{O}_{3}, \mathrm{CO}$

\section{Introduction}

Environmental pollution is emerging as one of national priorities with posing a growing threat to

${ }^{*}$ Corresponding author : Bu-Soon Son, Department of Environmental Health Science, Soonchunhyang University, Chungnam 336-745, Korea

Phone: +82-41-530-1270

E-mail: sonbss@sch.ac.kr lives and health of residents of industrial complexes (Ministry of Environment(MOE), 2000). Therefore, strengthened environmental policies have been implemented in a way to protect their environmental health(MOE, 2008). As environ- mental diseases including asthma and allergy are increasing among the residents of large-sized industrial complexes in Gwangyang, Sihwa, Ulsan and Pohang, investigations 
on environmental pollutions and their effects on the residents have been conducted for years(National Institute of Environmental Research(NIER), 2003-2008). In particular, those who live near petrochemical industrial complexes were reported to be suffering odor and other symptoms continuously, proving that air pollution at the region is serious(Seo et al., 2003). When air pollutions are inhaled or absorbed into the human body, the respiratory system contacts the pollutants directly. An on-going influence of the air pollutants on the system will weaken its self-defense function, causing various respiratory diseases(Shin et al., 2002). Air pollution has been known to increase acute respiratory diseases, lung malfunction, respiratory disease prevalence rate, hospitalization and related death rate. It also aggravates chronic respiratory diseases, asthma prevalence rate and asthma attack (Choi et al., 2000). Among others, the elderly, children, and those with health problems are the most vulnerable to the negative impacts of air pollution (Bae et al., 2008, 2009). The epidemiological investigation methods to evaluate effects of air pollution on the respiratory system are standardized questionnaire on respiratory symptoms, pulmonary function test and chest x-ray ( $\mathrm{Na}$ et al., 2009). Among them, pulmonary function test is widely used in air pollution epidemiology because of relatively low costs and convenience (Bae et al., 2004). Because PFT(pulmonary function test) values vary with gender, age, height, health, region and ethnicity, it is common that the test results are compared not with the absolute values but with the normal predictive values (Choi et al., 2005). Prior studies indicated that respiratory diseases and symptoms are caused and aggravated by genetic tendency and exposure to the environmental factors (Maier et al., 2000), they are known as the main source of respiratory diseases as they reduce lung function and cause allergies (Sotir et al., 2003). As Yeosu industrial complex has more heavy chemical and energy facilities than others, it has released large amount of $\mathrm{HCs}$ and $\mathrm{NO}_{\mathrm{x}}$ effluents into the air(Lee, 2005). Thereby, it was designated as an air quality regulated region in December 1999. This study conducted PFT and a survey on the residents in the Yeosu petrochemical industrial complex. The objective was to investigate environmental factors affecting lung function and respiratory symptoms of the residents while examining their relations. The study results will provide preliminary data for establishing responsive measures to protect health of the residents of industrial complexes from air pollution.

\section{Method}

\subsection{Subjects and Survey}

The study conducted from May 2007 to November 2007 by performing PFTs on the exposure group and the control group who are composed of residents within $5 \mathrm{~km}$ radius and $15 \mathrm{~km}$ radius of Yeosu Industrial Complex in South Jeolla respectively. In line with that, survey was conducted on their physical conditions, lifestyles, diseases, allergic symptoms, medical history and residential conditions to acknowledge other factors affecting pulmonary functions. The questionnaire of the survey developed by the National Institute of Environmental Research (Jeong et al., 2007) was utilized.

\subsection{Pulmonary function test}

For this study, Schiller model $\mathrm{SP}_{1}$ (Germany) was used. Before actual test, the subjects were fully educated with proper posture and use methods. And the tester demonstrated how to use the tool. Among other lung function values, $\mathrm{FVC}, \mathrm{FEV}_{1}$ and $\mathrm{FEV}_{1} / \mathrm{FVC}$ ratio was evaluated in this study. As for $\mathrm{FEV}_{1}$ and FVC, they were transformed into the percentpredicted value for forced expiratory volume in the one second (or $\mathrm{FEV}_{1}$ predictive value(\%)) adjusted with lung function, height, weight, gender and age of 
Korean people (Choi et al., 2005). The figure below shows the pulmonary function test standards.

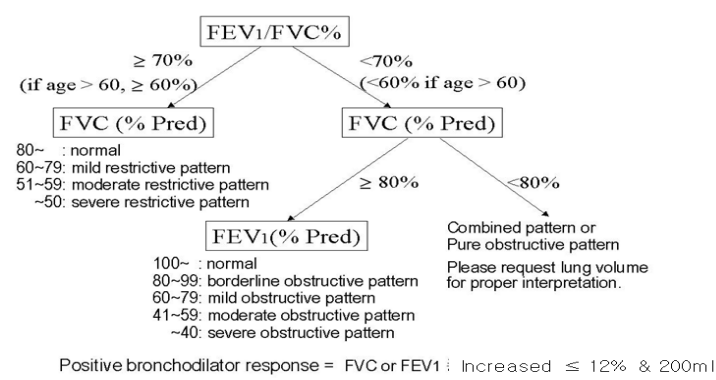

Fig. 1. Pulmonary function test standards.

\subsection{Decision Abnormal pulmonary function}

FVC is an indicator for restrictive ventilatory impairment and $\mathrm{FEV}_{1}$ is used to evaluate obstructive ventilatory impairment. But $\mathrm{FEV}_{1} / \mathrm{FVC}$ ratio must be considered to understand cause of decreases in FVC, because it can fall in case of airway obstruction (Table 1).

Patients with restrictive lung diseases record normal or higher than normal $\mathrm{FEV}_{1} / \mathrm{FVC}$ ratio because FVC drops. Obstruction Lung Disease or OLD refers to the disorders caused by obstruction in the airways. When $\mathrm{FEV}_{1} / \mathrm{FVC}$ ratio is less than 0.70 $(<0.70)$ and predicted $\mathrm{FEV}_{1}$ is lower than $80 \%(>80 \%)$, OLD is diagnosed (Cooper et al., 2010)18). In other words, OLD is diagnosed when $\mathrm{FEV}_{1} / \mathrm{FVC}$ is low, and it includes asthma, chronic obstructive bronchitis and pulmonary emphysema. Restrictive Lung Diseases or RLD refers to the conditions that lung and chest can't be fully expanded when inhaling. RLD is diagnosed when FVC is lower than $80 \%(<80 \%)$, although $\mathrm{FEV}_{1} / \mathrm{FVC}$ is 0.70 or higher $(\geqq 0.70)$. In other words, RLD is diagnosed when FVC is low despite normal $\mathrm{FEV}_{1} / \mathrm{FVC}$. Asbestosis, pulmonary congestion, pneumothorax and limits in breathing are included.
Table 1. Definitions of lung disease

\begin{tabular}{cccc}
\hline Pattern & $\begin{array}{c}\mathrm{FEV}_{1} \\
(\% \text { predicted })\end{array}$ & $\begin{array}{c}\text { FVC } \\
\text { (\% predicted })\end{array}$ & $\begin{array}{c}\mathrm{FEV}_{1} / \mathrm{FVC} \\
\text { ratio }\end{array}$ \\
\hline \hline Normal & $\geqq 80 \%$ & $\mathrm{NA}$ & $<0.70$ \\
Normal & $\mathrm{NA}$ & $\geqq 80 \%$ & $\geqq 0.70$ \\
Restricted & $\mathrm{NA}$ & $<80 \%$ & $\geqq 0.70$ \\
Obstructed & $<80 \%$ & $\mathrm{NA}$ & $<0.70$ \\
\hline
\end{tabular}

$\mathrm{FEV}_{1}$; forced expired volume in 1sec, FVC; forced vital capacity, NA; not applicable.

\subsection{Air pollution Monitoring Data}

Air pollution was analyzed based on the data obtained with the Air Pollution Monitoring Network (Gwangmu, Samildong, Wolaedong) from March 2003 to February 2007 (Ministry of Environment, 2007).

\subsection{Statistical analysis}

For the analysis on the biology samples and questionnaire results, SPSS ver. 18.0 and EXCEL were used. As for the differences between the exposure group and control group, and T-test was used. In case of the differences among more than three groups, ANOVA was utilized. To find out factors affecting the lung function, multiple regression analysis was used while logistic regression analysis was used for odds ratio.

\section{Results and Discussion}

\subsection{General characteristics of subjects}

Table 2 shows pulmonary function levels by gender, group and age. $\% \mathrm{FEV}_{1}$ and $\mathrm{FEV}_{1} / \mathrm{FVC}$ ratio is $103.38 \%$ and $81.56 \%$ among males and $109.21 \%$ and $84.24 \%$ among females respectively. As seen, males recorded lower levels compared to female subjects $(\mathrm{p}<0.001)$, but, $\% \mathrm{FVC}$ was higher among males with $101.64 \%$. Unlike prior expectation that males would post higher values than their female counterparts in the test, $\% \mathrm{FEV}_{1}$ and $\% \mathrm{FEV}_{1} / \mathrm{FVC}$ were higher among females. The result indicates that males recorded low 
$\% \mathrm{FEV}_{1}$ which represents forced respiratory volume in 1 second although they hight have better lung capacity. In other words, they have a high possibility of suffering asthma or other pulmonary diseases. That is because of following two reasons. First, more female participants in the age groups from 20 to 39 and 40 to 59. Second, males have a higher chance to be exposed to environmental factors through outdoor activities and lifestyles such as smoking. Lee(2009) wrote that male workers who had been exposed to small particles at workspace presented much lower pulmonary function values than others. From the study, we can assume that males have a higher risk to be exposed to factors reducing lung function at work too. As for the comparison between exposure group and control group, the exposure group posted $107.05 \%$ of $\% \mathrm{FEV}_{1}$ and $\% \mathrm{FVC}$ of $100.28 \%$, showing weaker lung capacity. Meanwhile the control group recorded $107.26 \%$ and $102.85 \%$. The study result shows that PFT values are lower among the exposure group than the control group, indicating that residents living near the industrial complexes are being exposed to the environmental factors reducing the lung function.

When factoring in age of subjects in the region, $\% \mathrm{FEV}_{1}$ becomes lower as they get younger $(\mathrm{p}<0.001)$. $\%$ FVC value was lowest among those aged from 20 to $39, \mathrm{FEV}_{1} / \mathrm{FVC}$ ratio decreased meaningfully in line with age increases $(\mathrm{p}<0.001)$. Murray et al.(2007) wrote that morphological changes such as reductions in lung elasticity and emphysema rise with aging.

Hong(2004) also wrote that functional reserve took place with aging, reducing the lung function. Goldman et al.(2004) also reported that $\% \mathrm{FEV}_{1}$ and

Table 2. Pulmonary function level according to Variables

\begin{tabular}{|c|c|c|c|c|}
\hline \multirow{2}{*}{ Variables } & \multirow{2}{*}{$\mathrm{N}(974)$} & $\% \mathrm{FEV}_{1}$ & $\% \mathrm{FVC}$ & $\% \mathrm{FEV}_{1} / \mathrm{FVC}$ \\
\hline & & \multicolumn{3}{|c|}{ Mean \pm S.D. } \\
\hline \multicolumn{5}{|l|}{ No. of subject } \\
\hline Male & 361 & $103.38 \pm 20.78$ & $101.64 \pm 17.30$ & $81.56 \pm 10.55$ \\
\hline Femlale & 628 & $109.21 \pm 24.96$ & $100.22 \pm 20.30$ & $84.24 \pm 8.91$ \\
\hline \multicolumn{2}{|r|}{ p-value } & $0.000^{* * *}$ & 0.263 & $0.000^{* * *}$ \\
\hline Exposure & 813 & $107.05 \pm 23.52$ & $100.28 \pm 19.46$ & $83.17 \pm 9.62$ \\
\hline \multirow[t]{2}{*}{ Non-exposure } & 176 & $107.26 \pm 24.47$ & $102.85 \pm 18.24$ & $83.67 \pm 9.65$ \\
\hline & p-value & 0.918 & 0.096 & 0.540 \\
\hline \multicolumn{5}{|l|}{ Age Group } \\
\hline$>9$ & 49 & $95.49 \pm 11.94$ & $98.10 \pm 12.64$ & $87.54 \pm 7.51$ \\
\hline $10 \sim 19$ & 314 & $96.68 \pm 15.27$ & $100.87 \pm 16.40$ & $86.04 \pm 8.59$ \\
\hline $20 \sim 39$ & 87 & $101.17 \pm 15.95$ & $95.83 \pm 14.01$ & $83.90 \pm 6.67$ \\
\hline $40 \sim 59$ & 193 & $113.18 \pm 20.19$ & $103.77 \pm 21.10$ & $82.33 \pm 8.56$ \\
\hline $60<$ & 346 & $116.26 \pm 29.19$ & $100.53 \pm 22.09$ & $80.50 \pm 10.98$ \\
\hline \multirow[t]{2}{*}{ Average } & 42 & & & \\
\hline & p-value & $0.000^{* * *}$ & $0.022^{*}$ & $0.000^{* * *}$ \\
\hline \multicolumn{5}{|l|}{ Smoking } \\
\hline No & 596 & $109.09 \pm 24.45$ & $101.56 \pm 16.41$ & $83.77 \pm 9.47$ \\
\hline \multirow[t]{2}{*}{ Yes } & 79 & $107.28 \pm 21.80$ & $100.86 \pm 19.81$ & $78.69 \pm 11.39$ \\
\hline & p-value & 0.491 & 0.729 & $0.000^{* * *}$ \\
\hline \multicolumn{5}{|c|}{ Passive smoking } \\
\hline No & 372 & $112.09 \pm 26.52$ & $102.43 \pm 18.64$ & $83.16 \pm 10.05$ \\
\hline \multirow[t]{2}{*}{ Yes } & 366 & $105.29 \pm 21.08$ & $98.93 \pm 20.39$ & $81.15 \pm 9.42$ \\
\hline & p-value & $0.000^{* * *}$ & 0.155 & 0.445 \\
\hline
\end{tabular}

${ }^{* *} \mathrm{p}<0.01,{ }^{* * *} \mathrm{p}<0.001$, S.D.; Standard Deviation, No.;Number 
FVC values went down due to aging. In this study, however, $\% \mathrm{FEV}_{1}$ increased and $\mathrm{FVC}$ became irregular. and $\% \mathrm{FEV}_{1} / \mathrm{FVC}$ in line with increases in age. $\% \mathrm{FVC}$ is an indicator for restrictive ventilatory impairment but it declines in case of airway obstruction. But, in this case, decreases in \% FVC coincided with decreases in $\% \mathrm{FEV}_{1} / \mathrm{FVC}$, indicating that possibilities of restrictive ventilatory impairment rises with increases in age. Smokers in this study posted $107.28 \%$ and $100.86 \%$ in $\% \mathrm{FEV}_{1}$ and $\% \mathrm{FVC}$ which were lower than the values of nonsmokers who recorded $109.09 \%$ and $101.56 \%$, respectively. As for $\mathrm{FEV}_{1} / \mathrm{FVC}$ ratio, smokers posted $83.77 \%$, while nonsmokers recorded $78.69 \%$, showing a meaningful difference $(p<0.001)$. Wen $(2005)$ reported that $\% \mathrm{FEV}_{1}$ decrease was associated with smoking. In addition the study found that complications found among the patients with weak lung function was also related to smoking. Park et al.(2009) compared smokers and non-smokers and found out that vital capacity decreased with smoking although the difference was not meaningful. Lee et al.(2000) also conducted a similar study respectively to find out that smoking reduced $\% \mathrm{FEV}_{1}$. Lee et al.(2000)'s study was conduced on former smokers and smokers and found out that the lung function was in a negative relation with smoking pack years. This study found $\% \mathrm{FEV}_{1}$ and $\% \mathrm{FVC}$ values were low among smokers, corresponding to other study results. But, tracking smoking experience only with a survey is limited. Although smoking is associated with decreases in the lung function, there are also many other causes affecting on the lung function. As for passive smoking, $\% \mathrm{FEV}_{1}$ and $\% \mathrm{FVC}$ values were lower among the respondents who are exposed to passive smoking with \%97.25 and $\% 98.53$. Those who are not exposed to passive smoking posed $\% 105.48$ and $\% 99.42$ respectively.

According to Mannino(2007) and Zlotkowska et al.(2004), children who had been exposed to passive smoking developed bronchitis more than others, showing that smoking of parents increased occurrence and frequency of respiratory diseases of their children. The study conducted by Whincup (2004) revealed that the exposure to passive smoking increased risk of chronic rhinosinusitis by $40 \%$. All in all, nonsmokers who had been exposed to passive smoking have a high chance of developing respiratory diseases. This study results showed that $\% \mathrm{FEV}_{1}$ and $\% \mathrm{FVC}$ values among those who had been exposed to passive smoking were lower like other studies.

\subsection{Pulmonary function by Factors}

\subsubsection{Resident's environment}

Table 3 show that influence of residential environment (distance between residence and a road, traffic amount, use of bed, pet breeding) on asthma diagnosis history rate, which can be utilized as an indirect index for the lung function. Asthma diagnosis history rate refers to the proportion of those who had been diagnosed with asthma before. And the odds ratio of asthma diagnosis history increased with traffic amount, the distance from road decreased, use of bed and under 4 family member. Park et al.(2003) reported that respiratory diseases were associated with traffic amount because the lung function decreased as the distance from road decreased and traffic amount increased. Those who were using bed recorded high the odds ratio of asthma diagnosis history, complying with the trend reported by Maier et al.(1997). This study results confirmed that traffic amount and use of bed have an influence on the lung function. The odds ratio of asthma diagnosis history decreased for those who were breeding a pet and had more than 4 family members. In Yeosu, a similar trend was found with pet breeding. Thereby, pet breeding and large family size seems to help increase immunity against asthma. And Park et al.(2003) found out chronic respiratory diseases and wheezing doubled when the family members were 3 and less. 
But the results were not statistically meaningful.

Table 3. The odds ratio of asthma diagnosis history according to Residence environment

\begin{tabular}{lcccc}
\hline Variables & $\begin{array}{c}\text { No. of } \\
\text { subjects }\end{array}$ & $\begin{array}{c}\text { Asthmatic } \\
\text { symptoms } \\
(\%)\end{array}$ & O.R. & $95 \%$ C.I. \\
\hline \hline $\begin{array}{l}\text { Distance from road } \\
\geqq 100 \mathrm{~m}\end{array}$ & 630 & $27(4.3)$ & & \\
$<100 \mathrm{~m}$ & 156 & $12(7.7)$ & 1.38 & $0.58-3.28$ \\
\hline $\begin{array}{l}\text { Traffic amount before house } \\
\leqq \text { Average }\end{array}$ & 675 & $33(4.9)$ & & \\
$>$ Average & 72 & $5(6.9)$ & 1.32 & $0.58-3.01$ \\
\hline $\begin{array}{l}\text { Bed use } \\
\text { No }\end{array}$ & 578 & $27(4.7)$ & & \\
$\quad$ Yes & 336 & $20(6.0)$ & 1.54 & $0.72-3.28$ \\
\hline $\begin{array}{l}\text { Breeding Pets at home } \\
\text { No }\end{array}$ & 376 & $19(5.1)$ & & \\
$\quad$ Yes & 532 & $26(4.9)$ & 0.98 & $0.44-2.16$ \\
\hline No. of Family member & & & \\
$\geqq 4$ & 558 & $27(4.8)$ & & \\
$<4$ & 209 & $11(5.3)$ & 1.03 & $0.45 .-2.37$ \\
\hline
\end{tabular}

$* * \mathrm{p}<0.01$, Wald test

\subsubsection{Respiratory and Allergic symptoms Questionnaire}

The odds ratio of abnormal pulmonary function according to respiratory (wheezing, asthma diagnosis history, wheezing during work-out) and allergic symptoms (nasal congestion, allergic eye disease, allergic rhinitis and allergic dermatitis) are seen in Table 4.

The odds ratio of abnormal pulmonary function was statistically high among those with asthma diagnosis history $(\mathrm{OR}=4.29, \quad \mathrm{CI}=1.75-10.56)$, wheezing $(\mathrm{OR}=2.59, \mathrm{CI}=1.24-5.41)$, nasal congestion $(\mathrm{OR}=2.87, \mathrm{CI}=1.36-6.08)(\mathrm{p}<0.01)$, wheezing during work-out $(\mathrm{OR}=1.12)$, allergic eye disease $(\mathrm{OR}=1.13$, $\mathrm{CI}=0.65-1.95)$ and allergic rhinitis $(\mathrm{OR}=1.09, \mathrm{CI}=$ $0.80-1.82$ ). Asthma diagnosis history is representative for all respiratory diseases. Wheezing refers to a high-pitched noise produced by movement of air through narrowed airways. This study found that the odds ratio of abnormal pulmonary function is extremely high among those with wheezing, or wheezing during work-out. This indicates that they are exposed to factors which can cause respiratory diseases or damage lung capacity, and asthma or wheezing are the symptoms. Nasal congestion is one of the most typical symptoms of allergic rhinitis, and indoor dust and outdoor air pollution may have an influence on it(Kim, 2006). It is generally known that about 10 to $15 \%$ of entire population is suffering allergic diseases(Jin et al., 2007). And allergic rhinitis has been rising because of increases in air pollution and environmental pollution.

Table 4. The odds ratio abnormal pulmonary function according to respiratory and allergic symptoms

\begin{tabular}{|c|c|c|c|c|}
\hline Variables & $\begin{array}{c}\text { No. of } \\
\text { subjects }\end{array}$ & $\begin{array}{l}\text { Abnormal } \\
\text { pulmonary } \\
\text { function }(\%) \\
\end{array}$ & O.R. & 95\% C.I. \\
\hline \multicolumn{5}{|c|}{ Asthma diagnosis history } \\
\hline No & 880 & $94(10.7)$ & & \\
\hline Yes & 48 & $14(29.2)$ & $4.29^{* *}$ & $1.75-10.56$ \\
\hline \multicolumn{5}{|l|}{ Wheezing } \\
\hline No & 762 & $74(9.7)$ & & \\
\hline Yes & 79 & $17(21.5)$ & $2.59^{* *}$ & $1.24-5.41$ \\
\hline \multicolumn{5}{|c|}{ Exercising wheezing } \\
\hline No & 768 & $95(12.4)$ & & \\
\hline Yes & 54 & $10(18.5)$ & 1.12 & $0.63-1.84$ \\
\hline \multicolumn{5}{|c|}{ Nasal obstruction } \\
\hline No & 828 & $5(4.9)$ & & \\
\hline Yes & 102 & $109(13.2)$ & $2.87^{* *}$ & $1.36-6.08$ \\
\hline \multicolumn{5}{|c|}{ Allergic eye disease } \\
\hline No & 643 & $34(12.5)$ & & \\
\hline Yes & 273 & $96(14.9)$ & 1.13 & $0.65-1.95$ \\
\hline \multicolumn{5}{|c|}{ Allergic rhinitis } \\
\hline No & 693 & $15(6.8)$ & & \\
\hline Yes & 222 & $92(13.3)$ & 1.09 & $0.80-1.82$ \\
\hline \multicolumn{5}{|c|}{ Atopy dermatitis } \\
\hline No & 766 & 21(18.4) & & \\
\hline Yes & 114 & $105(13.7)$ & 0.48 & $0.14-1.66$ \\
\hline
\end{tabular}

$* * \mathrm{p}<0.01$, Wald test

3.2.3. Multiple regression analysis of the factors influencing

To investigate the factors affecting the lung function of residents, a stepwise multiple regression analysis was conducted(Table 5). For the analysis, PFT values including $\mathrm{FEV}_{1}$ and $\mathrm{FVC}$ were dependent 
Table 5. Multiple linear regression by related variables of pulmonary function

\begin{tabular}{clcccccc}
\hline DV & \multicolumn{1}{c}{ IV } & $\beta$ & $S . E$ & $P$ & $\mathrm{R}^{2}$ & ${\text { Adj } R^{2}}^{\mathrm{F}_{\text {-value }}}$ \\
\hline \hline $\mathrm{FEV}_{1}$ & Asthma diagnosis history $^{\mathrm{b}}$ & -0.165 & 4.557 & 0.000 & 0.029 & 0.049 & $23.852^{* *}$ \\
& Passive smoking $^{\mathrm{a}}$ & -0.137 & 1.948 & 0.001 & 0.045 & \\
& Allergic eye disease $^{\mathrm{b}}$ & -0.091 & 2.215 & 0.022 & 0.054 & \\
\hline $\mathrm{FVC}$ & Asthma diagnosis history $^{\mathrm{b}}$ & -0.126 & 3.687 & 0.002 & 0.016 & 0.014 & $9.714^{*}$ \\
\hline
\end{tabular}

DV, dependent variable; IV, independent variable; SE, standard error, ${ }^{*} \mathrm{p}<0.001$ by F-test

${ }^{\mathrm{a}}$ smoking, Passive-smoking; $0=\mathrm{No}, 1=$ Yes, ${ }^{\mathrm{b}}$ nasal congestion, asthma, allergic rhinitis; $0=$ No, $1=$ Yes

variables. And independent variables were lifestyle (smoking, passive smoking), respiratory and allergic symptoms (asthma diagnosis history, wheezing, wheezing during work-out, nasal congestion, allergic eye disease, allergic rhinitis and allergic dermatitis).

As a result, the factors affecting $\mathrm{FEV}_{1}$ were symptoms including asthma diagnosis history, passive smoking and allergic eye disease $\left(\mathrm{R}^{2}=0.049\right.$, $\mathrm{p}<0.001)$ and FVC were symptoms including Asthma diagnosis history $\left(\mathrm{R}^{2}=0.014, \mathrm{p}<0.001\right)$. Prior studies reported that asthma is more common in the study area that others(NIER, 2008). Therefore, residents in the region might be sensitive to respiratory diseases such as asthma. Choi et al.(2008) reported decreases in lung capacity and increases in asthma severity among patients with cigaret smoking habits or smoking experience. They reported high frequent clinical symptoms. This study result shows that asthma is the biggest cause of decreasing lung capacity. And passive smoking and allergic diseases such as allergic eye diseases posted lower $\mathrm{FEV}_{1}$ and FVC. In conclusion, those who are suffering respiratory and allergic diseases were found to require special management methods.

\subsection{Air pollution and Pulmonary function level}

\subsubsection{Air pollution concentration}

Air pollution was analyzed based on the data obtained with the Air Pollution Monitoring Network from March 2006 to February 2007(Table 6).

Average concentration of $\mathrm{SO}_{2}, \mathrm{O}_{3}, \mathrm{NO}_{2}, \mathrm{CO}$ and $\mathrm{PM}_{10}$ were $10.77 \mathrm{ppb}, 28.39 \mathrm{ppb}, 17.58 \mathrm{ppb}, 6.01 \mathrm{ppm}$, and $44.72 \mu \mathrm{g} / \mathrm{m}^{3}$, below the air quality standards.

\subsubsection{Multiple regression analysis}

The controlling factors when conducting studies on relations between lung capacity and air pollution include age, gender, height, and asthma diagnosis history. Accordingly, correlations between air pollutants $\left(\mathrm{SO}_{2}, \mathrm{O}_{3}, \mathrm{NO}_{2}, \mathrm{CO}, \mathrm{PM}_{10}\right)$ and pulmonary function values $\left(\mathrm{FEV}_{1}, \mathrm{FVC}\right)$ was analyzed with controling individual factors (gender, age, asthma diagnosis history) in this study. The results are presented in Table 7.

The analysis showed that FVC decreased with increases in $\mathrm{O}_{3}$ and $\mathrm{CO}(\mathrm{p}<0.01)$. And, $\mathrm{FEV}_{1}$ decreased with increases in $\mathrm{O}_{3}$. Yeosu Industrial Complex is one of the largest petrochemical industrial site with highest production capacity in

Table 6. Air pollution concentration in Yeosu (Jan. 2006-Feb. 2007)

\begin{tabular}{lrrr}
\hline \multicolumn{1}{c}{ Air pollutant } & Environmental standard & Mean \pm S.D. & G.M. \\
\hline \hline $\mathrm{SO}_{2}(\mathrm{ppb})$ & $50(\mathrm{ppb} / 24 \mathrm{~h})$ & $6.13 \pm 2.15$ & 5.78 \\
$\mathrm{O}_{3}(\mathrm{ppb})$ & $60(\mathrm{ppb} / 8 \mathrm{~h})$ & $23.58 \pm 8.05$ & 22.06 \\
$\mathrm{NO}_{2}(\mathrm{ppb})$ & $60(\mathrm{ppb} / 24 \mathrm{~h})$ & $16.49 \pm 5.52$ & 15.49 \\
$\mathrm{CO}(\mathrm{ppm})$ & $9(\mathrm{ppm} / 8 \mathrm{~h})$ & $5.96 \pm 2.52$ & 5.51 \\
$\mathrm{PM}_{10}\left(\mu \mathrm{g} / \mathrm{m}^{3}\right)$ & $100\left(\mu \mathrm{g} / \mathrm{m}^{3} / 24 \mathrm{~h}\right)$ & $36.99 \pm 9.64$ & 35.70 \\
\hline
\end{tabular}

G.M. ; Geometric Mean, S.D. ; Standard Deviation 
Table 7. Estimates of the regression coefficients for Air pollutants using a mixed model by $\mathrm{FEV}_{1}, \mathrm{FVC}$

\begin{tabular}{|c|c|c|c|c|c|c|}
\hline \multicolumn{4}{|c|}{$\mathrm{FEV}_{1}$} & \multicolumn{3}{|c|}{ FVC } \\
\hline \multicolumn{7}{|c|}{$\overline{\mathrm{FEV}_{1}, \mathrm{FVC}}=\boldsymbol{\beta}_{0}+\boldsymbol{\beta}_{1}$ Gender $+\boldsymbol{\beta}_{2}$ Age $+\boldsymbol{\beta}_{3}$ Height ${ }^{+} \boldsymbol{\beta}_{4}$ Asthma ${ }^{+} \boldsymbol{\beta}_{5}$ Air pollutant } \\
\hline variable & $\boldsymbol{\beta}$ & SE & $\mathrm{t}$ & $\boldsymbol{\beta}$ & $\mathrm{SE}$ & $\mathrm{t}$ \\
\hline $\boldsymbol{\beta}_{0}$ & -4.52 & 1.67 & $-2.71^{* *}$ & -0.75 & 2.39 & $-2.40^{*}$ \\
\hline $\boldsymbol{\beta}_{1}$ & -0.23 & 0.13 & $-3.34^{* *}$ & -0.23 & 0.19 & $-2.77^{* *}$ \\
\hline $\boldsymbol{\beta}_{2}$ & -0.31 & 0.002 & $-5.51^{* * *}$ & -0.18 & 0.003 & $-2.72^{* *}$ \\
\hline $\boldsymbol{\beta}_{3}$ & 0.46 & 0.01 & $5.64^{* * *}$ & 0.45 & 0.01 & $4.78^{* * *}$ \\
\hline $\boldsymbol{\beta}_{4}$ & -0.11 & 0.18 & $-2.33^{*}$ & -0.06 & 0.26 & -1.07 \\
\hline $\boldsymbol{\beta}_{5}\left(\mathrm{SO}_{2}\right)$ & 0.06 & 0.01 & 1.23 & 0.16 & 0.06 & 1.19 \\
\hline $\boldsymbol{\beta}_{0}$ & -4.12 & 1.67 & $-2.46^{* *}$ & -5.69 & 2.44 & $-2.33^{*}$ \\
\hline $\boldsymbol{\beta}_{1}$ & -0.24 & 0.13 & $-3.46^{* *}$ & -0.23 & 0.19 & $-2.75^{* *}$ \\
\hline $\boldsymbol{\beta}_{2}$ & -0.31 & 0.002 & $-5.59^{* * *}$ & -0.20 & 0.003 & $-3.01^{* *}$ \\
\hline $\boldsymbol{\beta}_{3}$ & 0.46 & 0.01 & $5.72^{* * *}$ & 0.48 & 0.01 & $4.95^{* * *}$ \\
\hline $\boldsymbol{\beta}_{4}$ & -0.11 & 0.18 & -2.39 & -0.06 & 0.26 & -1.15 \\
\hline $\boldsymbol{\beta} 5\left(\mathrm{O}_{3}\right)$ & -0.42 & 0.01 & $-3.21^{* *}$ & -0.30 & 0.02 & $-2.24^{* *}$ \\
\hline $\boldsymbol{\beta}_{0}$ & -4.66 & 1.68 & $-2.76^{* *}$ & -6.13 & 2.43 & $-2.52^{*}$ \\
\hline $\boldsymbol{\beta}_{1}$ & -0.23 & 0.13 & $-3.31^{* *}$ & -0.22 & 0.19 & $-2.71^{* *}$ \\
\hline $\boldsymbol{\beta}_{2}$ & -0.23 & 0.002 & $-5.51^{* * *}$ & -0.20 & 0.003 & $-2.87^{* *}$ \\
\hline $\boldsymbol{\beta}_{3}$ & 0.47 & 0.01 & $5.85^{* * * *}$ & 0.49 & 0.01 & $5.05^{* * *}$ \\
\hline $\boldsymbol{\beta}_{4}$ & -0.11 & 0.18 & $-2.39^{*}$ & -0.06 & 0.27 & -1.19 \\
\hline $\boldsymbol{\beta}_{5}\left(\mathrm{NO}_{2}\right)$ & -0.01 & 0.01 & -0.16 & 0.02 & 0.01 & 0.27 \\
\hline $\boldsymbol{\beta}_{0}$ & -4.30 & 1.72 & -2.50 & -4.98 & 2.47 & $-2.02^{*}$ \\
\hline $\boldsymbol{\beta}_{1}$ & -0.24 & 0.13 & 0.41 & -0.25 & 0.19 & $-3.02^{* *}$ \\
\hline $\boldsymbol{\beta}_{2}$ & -0.33 & 0.002 & $-4.29^{* * *}$ & -0.23 & 0.003 & $-3.34^{* *}$ \\
\hline $\boldsymbol{\beta}_{3}$ & 0.45 & 0.01 & $3.33^{* *}$ & 0.45 & 0.13 & $4.67^{* * *}$ \\
\hline $\boldsymbol{\beta}_{4}$ & -0.11 & 0.18 & -1.69 & -0.07 & 0.27 & -1.32 \\
\hline $\boldsymbol{\beta}_{5}(\mathrm{CO})$ & -0.13 & 0.02 & -1.44 & -0.11 & 0.02 & $-2.29^{* *}$ \\
\hline $\boldsymbol{\beta}_{0}$ & -4.37 & 1.67 & -2.62 & -5.74 & 2.43 & $-2.36^{*}$ \\
\hline $\boldsymbol{\beta} 1$ & -0.24 & 0.13 & $-3.44^{* *}$ & -0.24 & 0.19 & $-2.84^{* *}$ \\
\hline $\boldsymbol{\beta}_{2}$ & -0.34 & 0.002 & $-5.98^{* * *}$ & -0.20 & 0.003 & $-2.97^{* *}$ \\
\hline $\boldsymbol{\beta}_{3}$ & 0.47 & 0.01 & $5.83^{* * *}$ & 0.47 & 0.01 & $4.84^{* * *}$ \\
\hline $\boldsymbol{\beta}_{4}$ & -0.11 & 0.18 & $-2.46^{*}$ & -0.06 & 0.27 & -1.16 \\
\hline $\boldsymbol{\beta}_{5}\left(\mathrm{PM}_{10}\right)$ & -0.07 & 0.03 & -1.44 & 0.02 & 0.01 & 0.42 \\
\hline
\end{tabular}

$* \mathrm{p}<0.05, * * \mathrm{p}<0.01, * * * \mathrm{p}<0.001$, S.E : Standard error

Korea(Korea Industrial Complex Corp., 2009). Being integrated into Gwangyang district, Yeosu has Gwangyang steel mill and Hadong thermal power plant on its northern edge. Because of vessels in the Gwangyang Bay, VOCs and NOx, precursors of $\mathrm{O}_{3}$, are released into the air(Lee, 2005; Jeon et al., 2004). According to $\mathrm{Ha}$ et al.(2006) and Lee et al.(2005), $\mathrm{O}_{3}$ created by precursors such as NOx and VOCs is contaminating ambient air of Gwangyang District. $\mathrm{An}(2002)$ wrote that $\mathrm{O}_{3}$ concentration decreases lung capacity. In particular, Kim et al.(2010) reported that even low concentration of $\mathrm{O}_{3}$ can damage respiratory function of asthma patients. Meanwhile, CO concentration is high in the air of industrial sites burning huge amount of coal or oil. CO is created by incomplete combustion of carbon compounds. According to Mun et al.(2009), when CO concentration adds $0.12 \mathrm{ppm}$, symptoms of allergy and asthma increased by $0.4-0.6 \%$. Choi et al.(2000) and Kang et al.(2000) reported rises in ER visits due to respiratory diseases when concentration of $\mathrm{CO}, \mathrm{SO}_{2}$, and $\mathrm{O}_{3}$ increase. The reason behind high concentration of $\mathrm{O}_{3}$ 
and $\mathrm{CO}$ in Yeosu and their impacts on lung capacity of residents was that it is isolated by Gwangyang Bay and has more petrochemical industrial facilities than others. Considering that $\mathrm{FEV}_{1}$ and $\mathrm{FVC}$ values of residents have been decreased due to $\mathrm{O}_{3}$ and $\mathrm{CO}$ in the area, national policies to deal with those pollutants are required to be implemented to protect their environmental health.

\section{Conclusion}

This study conducted pulmonary function tests, medical examinations and surveys on residents of the Yeosu Industrial Complex, from May 2007 to November 2007 in the Gwangyang District, to analyze effects of ambient air pollutants on the pulmonary function.

The followings are the results of the study.

1. Analysis on pulmonary test results found that males recorded lower values with posting $103.38 \%$ of $\% \mathrm{FEV}_{1}$ and $81.56 \%$ of $\mathrm{FEV}_{1} / \mathrm{FVC}$ ratio while their counterparts posted $109.21 \%$ and $84.24 \%(\mathrm{p}<0.001)$. But, FVC was higher among males with $101.64 \%$.

2. When comparing PFT values of the exposure groups to the control group of the same city, values of the exposure groups are meaningfully lower with $\% \mathrm{FEV}_{1}$ of $107.05 \%$ and $\mathrm{FVC}$ of $100.28 \%$ than the control group whose $\% \mathrm{FEV}_{1}$ and $\% \mathrm{FVC}$ was $107.26 \%$ and $102.85 \%$ respectively, indicating that ambient air pollutants reduce lung function.

3. Asthma odds ratio increased when residence was close to a heavy traffic road, traffic amount was huge, bed was used, and family had lesser than four members. But the result was not statistically meaningful.

4. Pulmonary function odds ratio was statistically high among those with asthma $(\mathrm{OR}=4.29, \mathrm{CI}=$ 1.75-10.56), wheezing $(\mathrm{OR}=2.59, \mathrm{CI}=1.24-5.41)$, nasal congestion $(\mathrm{OR}=2.87, \mathrm{CI}=1.36-6.08)(\mathrm{p}<0.01)$, wheezing during work-out $(\mathrm{OR}=1.12, \mathrm{CI}=0.63$ 1.84), allergic eye disease $(\mathrm{OR}=1.13, \mathrm{CI}=0.65-1.95)$ and allergic rhinitis(OR=1.09, $\mathrm{CI}=0.80-1.82)$.

5. The factors affecting $\mathrm{FEV}_{1}$ were symptoms including asthma, passive smoking and allergic eye disease $\left(\mathrm{R}^{2}=0.049, \mathrm{p}<0.001\right)$ and $\mathrm{FVC}$ were symptoms including asthma $\left(\mathrm{R}^{2}=0.014, \mathrm{p}<0.001\right)$.

6. The analysis showed that FVC decreased with increases in $\mathrm{O}_{3}$ and $\mathrm{CO}(\mathrm{p}<0.01)$. And, $\mathrm{FEV}_{1}$ decreased with increases in $\mathrm{O}_{3}(\mathrm{p}<0.01)$.

This study results will provide preliminary data for establishing responsive measures to protect health of the residents of industrial complexes from air pollution and developing environmental health policies.

\section{Reference}

Ahn, J. H., 2002, A Study on Relationship between Ambient Air pollutants and Pulmonary Function in the Seoul Area, Master Dissertation, Hanyang University.

Bae, H. J., Kim, M. H., Lee, A. K., 2009, Acute Effects of $\mathrm{PM}_{10}$ on Asthma Hospitalization Among Children and Benefit Analysis at Major Cities in Korea, J. Env. Hlth. Sci., 35(1), 1-10.

Bae, H. J., Ha, J. S., Lee, A. K., Park, J. I., 2008, Age Dependencies in Air Pollution-associated Asthma Hospitalization, J. Env. Hlth. Sci., 34(2), 124-130.

Bae, K. W., Kim, Y. S., Park, J. S., Lee, K. Y., Kwon, H. J., Lee, S. R., Jee, Y. K., 2004, Change of Lung Function and Symptoms of Asthmatics according to the Concentration of On site Measured $\mathrm{NO}_{2}$, Kor. J. Asthma, Allergy Clin. Immunol., 24(3), 324-330.

Choi, H., Lim, D. H., Kim, J. H., Son, B. G., Lim, J. H., Hong, Y. C., 2000, Study on the Interrelationship of Air Pollution and Respiratory Diseases in Inchon City Via Children Who Visited the Emergency Room of Inha University Hospital, J. Korean Pediatr. Assoc., 43(10), 1372-1379.

Choi, J. G., Back, D. M., Lee, J. O., 2005, Normal Predictive Values of Spirometry in Korean 
Population, Tuberc. Respir. Dis., 58(3), 230-242.

Choi, J. K., Kang, S. H., Park, Y. H. Bae, Y. J., Kim, T. B., Lee, T. H., Park, C. S., Moon, H. B., Cho, S. H., Park, H. W., Jang, Y. S., 2008, Pulmonary Function and Clinical Characteristics Influenced by Cigarette Smoking among Adult Asthmatics, Kor. J. Asthma, Allergy Clin. Immunol., 28(4), 263-270.

Cooper, B., 2010, Spirometry standards and $\mathrm{FEV}_{1} / \mathrm{FVC}$ repeatability, Prim. Care Respir. J., 19(3), 292-294.

Ha, H., Lee, S. D., Lee, J. K., Park, C. O., Mun, T. R., 2006, On Characteristics of Surface Ozone Concentration and Temporal - Spatial Distribution in Gwangyang-Bay, Kor. Soc. Atm. Environ, 22(5), 642-652.

Hong, C. G., 2004, Comparison of Pulmonary Function of Adolescence Associated with Exposure to Smoking, Master Dissertation, Keimyung University.

Jang, M., Oh, J. R., Choi, D. L., Sin, K. S., Choi, J. W., 2003, A study on the management model for environmental pollution of special management area in Namhae; ( I ) Gwangyang Bay study, Korea Ocean Research \& Development Institute, Gyeonggi-do.

Jeon, J. M., Hur, D., Hwang, I. J., Kim, D. S., 2004, Estimation of Source Contribution for VOCs by the Chemical Mass Balance Model in the Yeosu Petrochemical Industrial Complex, Proceeding of the 37th conference, Kor. Soc. Atm. Environ., 61-62.

Jeong, H. G., Kim, S. Y., Kim, E. H., Sin, M. H., 2007, Standardization question and input systematic development for Environmental Health field, Korean J. Occup. Environ. Med., 151-152.

Jin, S. H., Kim, E. O., Park, K. S., 2007, Sensitization to House Dust Mite: Its Associations with Bronchial Hyperresponsiveness and Lung Function In Asthmatic Children, Pediatr. Allergy Respir. Dis., 17(4), 362-371.

Kang, S. K., Lim, D. H, Kim, J. H., Son, B. K., Lim, J. W., Hong, Y. C., 2001, Relationship of air pollution and pediatric respiratory disease in Incheon city, Pediatr. Allergy Respir. Dis., 11(4), 354-362.

Kim, J. H., Oh, S. K., Seong, H. U., Lim, D. H., Son, B. K., Kim, H. C., Lee, J. Y., Lim, J. H., 2010, Relationship Between Air Pollutants and Prevalence of Allergic Disease/Pulmonary Function in Students in Incheon, Pediatr. Allergy Respir. Dis., 20(4), 264-276.
Lee, H. S., Kim, N. Y., Lim, D. H., Joo, H. D., Lee, J. B., Kam, S., Yeh, M. H., 2000, Effect of smoking on pulmonary function in ex-smokers and current smokers, J. Korean Acad. Fam. Med., 21(2), 211-221.

Lee, J. H., Oh, I. B., Sim, C. S., Kim, Y. H., Yoo, C. I., 2010, An Association Between Air Pollution and Prevalence of Allergic Rhinitis in the Ulsan Metropolitan Region, J. Env. Hlth. Sci., 36(6), 465-471.

Lee, J. M., 2005, Numerical simulation modeling of ozone concentration in Gwangyang bay, Master Dissertation, Mokpo National University.

Lee, J. M., 2005, Numerical simulation modeling of ozone concentration in Gwangyang bay, Ph.D. Dissertation, Mokpo National University.

Lee, J. O., 2009, A Study on Annual Lung Function Changes in Workers Formerly Exposed to Dust, Master Dissertation, Yong-in University.

Lee, S. D., Mun, T. T., 2006, Numerical Simulation of Effect on Atmospheric Flow Field by Development of Coastal Area, J. of the Environmental Science, 15(10), 919-928.

Maier, W. C., Arrighi, H. M., Morray, B., 1997, Indoor risk factors for asthma and wheezing among Seattle school children, Environ. Health Perspect., 105(2), 208-214.

Mannino, D. M., Moorman, J. E., Kingsley, B., 2001, Health effects related to environmental tobacco smoke exposure in children in the United States: Data From the Third National Health and Nutrition Examination Survey, Arch. Pediatr. Adolesc. Med., 155(1), 36-41.

Ministry of Environment, 2000, Environment white paper. Ministry of Environment, 2008, Environment white paper.

Moon, J. S., Kim, Y. S., Son, B. S., Kim, D. S., Yang, W. H., 2009, Respiratory health effects among schoolchildren and their relationship to air pollutants in Korea, Int. J. Environ. Health Res., 19(1), 31-48.

Na, W. T., Park, J. H., Lee, G. E., Kwon, S. J., Son, J. W., Na, M. J., Choi, E. G., 2009, Comparison of spirometry with cardiopulmonary exercise test of chronic obstructive pulmonary disease, Korean J. Med., 76(5), 571-577.

National Institute of Environmental Research(NIER), 2003-2008, Monitoring on exposure level and 
bio-maker of environment pollutants for industrial residence.

Park, H. S., Lee, B. E., Ha, E. H., Kim, N. H., Hong, Y. C., Lee, Y. K., Cho, Y. S., 2003, Prevalence and environmental risk for respiratory symptoms among elementary school children in a city, J. of Korean Soc. of School Health, 16(2), 1-11.

Park, S. J., Kim, J. Y., Shin, W. J., 2009, Comparative Study of Non-Smoke Group and Smoke Group by Diagnosis System of Oriental Medicine, Korean J. Oriental Physiology \& Pathology, 23(2), 505-511.

Seo, B. R., Jeong, K. H., Hur, D., Koh, O. S., Jeong, M. H., Jeon, J. M., 2006, Evaluation of Odor EmissionSource from Petrochemiclal Plant in Yeosu Industrial Complex, Proceedings of the 41st conference, Kor. Soc. Atm. Environ., 276-277.

Shin, J. S., Jeon, S. R., 2002, A Comparative Study on the Health Status of the Elementary Students Living in a certain Industrial area and a certain Residential area in Busan, J. of Korean Soc. of School Health, 15(2), 263-275.

Sotir, M., Yeatts, K., Shy, C., 2003, Presence of asthma risk factors and environmental exposures related to upper respiratory infection-triggered wheezing in middle school-age children, Environ. Health Perspect., 111(4), 657-662.

Wen, Q. G., 2005, The Interactions Between Cigarette Smoking and Reduced Lung Function on Systemic Inflammation, Chest, 127(2), 558-564.

Whincup, P. H., Gilg, J. A., 2004, Emberson, J. R., Passive smoking and risk of coronary heart disease and stroke: prospective study with cotinine measurement, BMJ, 329(7459), 200-205.

Zlotkowska, R., Przeglad, L., 2004, Passive smoking, atopy and respiratory health in schoolchildren, Przegl. Lek., 61(10), 1057-1060. 